\title{
INFÂNCIA EM AFROPERSPECTIVA: ARTICULAÇÕES ENTRE SANKOFA, NDAW E TERRIXISTIR
}

Renato Noguera

\begin{abstract}
Resumo: O objetivo deste artigo é examinar a infância - entendida como um modo de vida - dentro de um contexto filosófico afroperspectivista, correlacionando-o com a ideia de sankofa, o conceito de ndaw e a categoria educativa terrixistir. A partir de uma leitura dos estudos de Cheik Anta Diop, da afrocentricidade, do perspectivismo ameríndio, do quilombismo e diálogos com diversas referências africanas o texto procura sustentar uma hipótese bem simples: a superação da adultidade pode ser feita através da infancialização. Daí, a arquitetura conceitual especulativa subsidiar filosoficamente princípios para uma educação afroperspectivista que proponha uma conexão com a terra como condição de existir. Daí, a infância emerge como um "milagre" que afasta a existência da adulteração corrupta da adultidade.
\end{abstract}

Palavras-Chave: Infância; Afroperspectiva; Sankofa; Ndaw; Terrexistir

RESUMEN: El objetivo de este artículo es examinar la infancia - entendida como un modo de vida dentro de un contexto filosófico afroperspectivista, correlacionando con la idea de sankofa, el concepto de ndaw y la categoría educativa terrixista. A partir de una lectura de los estudios de Cheik Anta Diop, de la afrocentricidad, del perspectivismo amerindio, del quilombismo y diálogos con diversas referencias africanas, el texto procura sostener una hipótesis bien simple: la superación de la adultidad puede ser hecha a través de la infancialización. De ahí, la arquitectura conceptual especulativa subsidiar filosóficamente principios para una educación afroperspectivista que proponga una conexión con la tierra como condición de existir. De ahí, la infancia emerge como un "milagro" que aleja la existencia de la adulteración corrupta de la adultidad.

Palabras clave: Infancia; Afroperspectiva; Sankofa; Ndaw; Tierrexistir

Existe uma evidência incontestável de que há entre crianças um espírito que se recusa a ser subjugado. ${ }^{1}$ Angela Davis

\section{Primeiras palavras}

Este ensaio seguirá na primeira pessoa do plural ${ }^{2}$, invocando uma escrita afroperspectivista $^{3}$ que se pretende infanciali-

\footnotetext{
${ }^{1}$ DAVIS, Angela. Mulheres, cultura e política, p. 96.

${ }^{2}$ Nós sempre falamos através de intercessores, por meio e com outras pessoas, com referências diversas. 3 O nosso referencial teórico basilar é a afroperspectividade, uma construção coletiva em curso que foi apresentada nos livros Ensino de filosofia e a Lei 10639 (NOGUERA, Renato, 2014) e Sambo, logo penso: afroperspectivas filosóficas para pensar o samba
}

zante. A epígrafe que abre este artigo é um convite. Diante do qual, cabe perguntar: as crianças carregariam uma insubordinação radical diante de todas as circunstâncias de opressão? A filósofa Angela Davis afirma que sim. Daí, surgiria a necessidade de ouvirmos as crianças sobre as grandes questões, um tipo de investigação interessada na autonomia intelectual de pessoas de todas as gerações. Dito isso, vale ressaltar que

(SILVA, Wallace Lopes, 2014) ambos premiados pelo Edital de Apoio à Coleção de Livros de Autores Negros da Fundação Biblioteca Nacional, Ministério da Cultura, em parceria com a Secretaria de Políticas de Promoção da Igualdade Racial da Presidência da República.

NOGUERA, Renato. Infância em afroperspectiva: articulações entre sankofa, ndaw e terrixistir. Revista Sul-Americana de Filosofia e Educação. Número 31: mai.-out./2019, p. 53-70. DOI: https://doi.org/10.26512/resafe.vi3o.28256 
partiremos de uma consideração filosófica afroperspectivista que toma a infância como sujeito interrogante.

Uma maneira de partirmos da infância como perspectiva de investigação está nas interpretações sobre uma tradicional narrativa da África ocidental, incluindo vários povos como wolof, senufo, bambara, mandinga, a célebre história Kiriku e a feiticeira ${ }^{4}$. Nessa trama a mensagem fundamental está associada à capacidade de Kiriku, a menor criança da aldeia, resolver os maiores problemas. No final da trama Kiriku deixa de ser criança e torna-se um adulto. O que é uma pista importante para nossa interpretação de que a história está a falar mais de infância do que propriamente das crianças. De qualquer modo, filosoficamente defendemos que as crianças estariam mais frequentemente em "estado de infância", enquanto o "adultescimento" seria justamente o desvirtuamento desse estado, uma característica que envolve as pessoas no processo de "amadurecimento" e "desenvolvimento". Em outras palavras, estamos a criticar as noções de desenvolvimento, avanço e progresso; investindo na ideia de que é mais importante mantermo-nos em estado de infância. Temas que voltaremos adiante.

\footnotetext{
${ }^{4}$ Kiriku e a feiticeira retrata uma história tradicional da África ocidental em que um recém-nascido que nasce falando, andando e correndo muito rápido se incumbe de salvar a sua aldeia de Karabá, uma feiticeira terrível que deu fim a todos os guerreiros da aldeia, secou a sua fonte d'água e roubou todo o ouro das mulheres. Kiriku é tratado de forma ambígua pelas pessoas de sua aldeia, por ser um bebê, é desprezado pelos mais velhos quando tenta ajudá-los, porém, quando realiza atos heroicos, suas façanhas são muito comemoradas, embora logo em seguida voltem a desprezá-lo. Apenas a sua mãe lhe trata de acordo com sua inteligência.
}

De antemão vale registrar que não vamos explorar exatamente a categoria "crianças", apenas faremos alusão a elas como modo de interrogar a infância. A nossa hipótese é uma aposta: estar em estado de infância (ndaw $)^{5}$ cria condições mais favoráveis para consolidação de uma política aqui denominada, aqui somente de modo preliminar, de terrexistir ${ }^{6}$ através do conceito de sankofa 7 .

\section{Referencial teórico}

Afroperspectividade é uma cosmosensação policêntrica ${ }^{8}$, uma abordagem polirracional ${ }^{9}$ que se orienta com pretensão à

\footnotetext{
5 Ndaw significa infância na língua wolof. O radical da palavra, daw, significa correr, percorrer. Infância remete à ideia de estar em movimento, percorrendo caminhos.

${ }^{6}$ Terrexistir é um conceito sugerido pelo biólogo e doutor em Educação, Celso Sánchez da Universidade Federal do Estado do Rio de Janeiro (Unirio) após um diálogo feito em 2016, Sanchez sugeriu que minha apresentação incorporasse essa noção e adiante em 2018, nós escrevemos juntos a primeira definição strictu sensu do conceito. Aqui terrixistir aparece apenas como uma noção preliminar e ainda em construção.

7 Sankofa significa voltar e buscar o que ficou para trás na língua twi.

${ }^{8}$ Policêntrica é uma leitura crítica e dialógica baseada nas considerações da pensadora nigeriana Oyeronke Oyewumi.

9 Polirracional é uma menção ao recorte teórico do filósofo ugandense Dismas Masolo (2010). O conceito contrasta com a categoria de monorracional, isto é, uma ideia de que a "Razão" humana seria monolítica e dona de uma percepção unitária e exclusivista. Polirracionalidade seria justamente uma perspectiva de que a razão humana é plural, composta de "sistemas" variados e multidimensionais de racionalidades. Por exemplo, em algumas culturas, a racionalidade percebe o tempo como um fluxo contínuo no sentido do futuro. Em outras, a racionalidade compreende que o tempo presente interfere no passado, tal como na cosmovisão ioruba.
} 
pluriversalidade $\mathrm{e}^{10}$, uma abordagem teórica e metodológica que surge no contexto das Ciências Humanas tendo como inspirações, o quilombismo de Abdias do Nascimento, a afrocentricidade na formulação de Molefi Asante e o perspectivismo ameríndio ${ }^{11}$ pensado pela antropóloga Tânia Stolze Lima. Vale aqui destacar alguns elementos de cada abordagem para constituição do mosaico afroperspectivista.

O antropólogo Eduardo Viveiros de Castro durante o ato Abril Indígena na Cinelândia, Rio de Janeiro-RJ, em 20 de abril de 2016 fez várias considerações do nosso interesse durante sua aula pública intitulada "Os involuntários da Pátria". Viveiros de Castro contrapôs os termos "indígena" e “alienígena”; defendendo que indígenas são pessoas que olham todas as coisas como agentes, porque são imanentes e estão localizadas. Elas são pessoas que não têm terra; mas, pertencem à terra. Indígenas são anteriores à colonização, nativo no sentido de pertencente a terra, nunca o contrário. Em oposição, "alienígenas" seriam justamente seres que chegam de fora, sem terra, desvinculados do lugar que estão. $\mathrm{O}$ que, em certa medida, parece justamente com a ideia moderna de "cidadania", condição de súdito de um Estado soberano. Esse Estado que olha cidadãs e cidadãos de cima, concedendo-lhes alguns direitos. É importante registrar que Viveiros de Castro afirmou que

\footnotetext{
${ }^{10}$ Pluriversal é uma menção à perspectiva ontológica do pensador Mogobe Ramose. Uma formulação que se opõe à ideia de universal, argumentando que essa tese é controversa porque supõe a existência de uma perspectiva única e monolítica.

${ }^{11}$ Perspectivismo ameríndio é uma construção teórica e metodológica feita por Tânia Stolze Lima e Eduardo Viveiros de Castro.
}

a formulação sistematizada do perspectivismo ameríndio nasceu de diálogos com Tânia Stolze Lima, sua orientanda de mestrado e doutorado. O perspectivismo ameríndio faz um deslocamento que não pode ser visto formalmente. Ao invés de pressupor a existência de uma natureza sobre a qual as populações humanas produzem culturas distintas, o que implicaria no multiculturalismo. Tânia Stolze Lima e Eduardo Viveiros de Castro partem de etnologias amazônicas para inferir a existência de uma só cultura através da qual os corpos se instalam. O que sugere um multinaturalismo. Em linhas gerais, isso implica numa ruptura radical com hierarquizações entre os seres vivos, sem recorrer ao princípio iluminista: "somos todos iguais". De modo que existiria uma natureza universal e diferenças no registro da cultura. Ora, "a concepção ameríndia suporia, ao contrário, uma unidade do espírito e uma diversidade dos corpos. A cultura ou o sujeito seriam aqui a forma do universal, a natureza ou o objeto a forma do particular" (CASTRO, 2002, p.226).

Num outro registro, o multifacetado Abdias do Nascimento trouxe uma contribuição notável com a tese do quilombismo. A partir da proposta de mobilização política em que o Quilombo é a referência, Nascimento definiu-o como reunião fraterna e livre, convivência e comunhão existencial. Daí, o quilombismo constituir-se como um comunitarismo de tradição africana em que o conflito é reconhecido como componente das relações humanas; mas, não significa razão para estabelecer adversários rivais. Em outras palavras, o quilombismo não é um projeto político fantasioso, um conto de fadas romântico em que todas as pessoas 
“vivem felizes para sempre". Porém, uma abordagem crítica que propõe uma articulação criativa em que a terra seja de uso coletivo. Uma das bases convocadas por Nascimento é o princípio denominado ujamaa que significa em suaíli algo como "compartilhar recursos". Esse princípio circunscreve várias noções e diz respeito ao enfrentamento da existência como uma tarefa interdependente. Um exercício que obriga as pessoas a conviverem e compartilharem experiências.

Molefi Asante afirmou que Abdias do Nascimento foi um dos seus mestres ${ }^{12}$. Asante sistematizou um paradigma que tem angariado críticas e elogios, a afrocentricidade é uma construção teórica e metodológica pan-africanista. Os seus elementos mais característicos estão nas categorias, localização e agência. Afrocentricidade afirma que o pertencimento identitário de um povo ou de uma pessoa é constituído pela sua história, sua cultura e sua ancestralidade. O conceito de centro ou "estar centrada" diz respeito à capacidade de se manter dentro desses três eixos, histórico, cultural e ancestral. Neste sentido, a identidade africana é baseada na ancestralidade. É importante destacar que "africana" e "africano" não são, apenas, categorias geográficas; mas, conceitos políticos. Por sua vez, agência diz respeito ao uso dos recursos psicológicos e de toda ordem em favor da promoção da liberdade humana, o que só é viável a partir do momento em que uma pessoa está localizada em sua centricidade ances-

\footnotetext{
${ }^{12}$ No ano de 2010, eu participei da Conferência Cheikh Anta Diop na Universidade da Filadélfia e Molefi Asante fez questão de frisar que Abdias do Nascimento foi um dos seus mentores.
}

tral, cultural e histórica. Conforme Asante (2013, p.23): “centricidade refere-se a uma perspectiva que implica recolocar os estudantes no contexto das suas referências culturais”. Ora, diante do racismo antinegro é urgente fazermos uma reconexão com algo que foi perdido.

Pois bem, como articular referencias tão distintas? De modo bastante resumido. Nós assumimos alguns pontos de vistas das formulações teóricas mencionadas e de trabalhos em curso feitos com crianças ${ }^{13}$. Daí, o argumento pode ser descrito assim. Com base em Tânia Stolze Lima, recolocamos como "universal", ou ainda, condição compartilhada - o estado de infância. Partindo de Asante, o qual reclama a necessidade de que os povos mantenham a centricidade em ancestralidade, história e cultura, ressaltando como isso é decisivo para as pessoas africanas que foram descentralizadas. Nós propomos uma centricidade no estado de infância como possibilidade de uma agência em favor de todos os seres vivos. Com a formulação de que os modelos vigentes de sociedade são adversários de uma condição humana fundamental, o estado de infância. Em seguida, o quilombismo de Abdias do Nascimento nos inspirou a afirmar que uma civilização ujamaaísta só é possível quando

\footnotetext{
${ }^{13}$ Pesquisas de campo feitas através do projeto Infância falante. O projeto consiste numa série de rodas de conversas com crianças de 5 a 12 anos em contextos e territórios distintos em várias regiões brasileiras. Uma pesquisa iniciada em 2017 e sem prazo para término. A pesquisa começou envolvendo uma instituição de cada região do país; mas, em seis meses a quantidade de participantes dobrou. Na ocasião de publicação do livro, nenhum relatório parcial estava pronto.
} 
o horizonte cosmopolítico for o estado de infância.

\section{As crianças, bastiões da resistência}

A filósofa Angela Davis publicou em 1990 uma série de ensaios sob o título $\mathrm{Mu}$ lheres, cultura e política. O capítulo "Destruindo o sonho: a família negra e a crise do capitalismo" foi escrito em parceria com sua irmã, Fana Davis. Segue um trecho:

Em todas as culturas do mundo, as crianças representam a promessa de riquezas materiais e espirituais que suas mães e seus pais foram incapazes de alcançar. A cultura afroamericana não é exceção e, como afirma a personagem de Lorraine Hansberry ${ }^{14}$, as crianças tornam mais possíveis aquelas grandes aspirações de progresso que não estão ao alcance de seus progenitores. Nas palavras frequentemente citadas de José Martí, "as crianças são a esperança do mundo".

Ao longo dos séculos que se seguiram à transferência forçada do povo africano de sua terra natal para os Estados Unidos, as crianças representaram a maior esperança uma promessa muito especial de liberdade para um povo inteiro. Mesmo quando os esforços da população negra para manter e estreitar seus laços familiares eram cruelmente atacados, a família continuava sendo um importante caldeirão de re-

\footnotetext{
${ }^{14}$ Angela Davis faz menção a uma das peças de Lorraine Hansberry (1930-1965), dramaturga e escritora afro-americana que recebeu o New York Drama Critics Circle Award. Em especial menciona a saga da família Younger na peça $A$ Raisin in the Sun escrita em 1959. O trabalho premiado foi para o cinema em 1961, no Brasil traduzido como: O Sol tornará a brilhar. Na trama uma família sofre racismo antes mesmo de se mudar para um bairro branco de classe média.
}

sistência, gerando e preservando o legado vital da luta coletiva por liberdade (DAVIS; DAVIS, 2017, p. 69).

O trecho das irmãs Davis ajuda-nos a caminhar numa leitura filosófica da infância no contexto africano e da sua diáspora. O que elas dizem a respeito das crianças negras nos Estados Unidos aplica-se ao Brasil e, indo mais longe, a toda diáspora africana. A frase de José Martí que aparece no texto, "as crianças são a esperança do mundo", merece uma análise filosófica mais detida. Ora, o que isso quer dizer? Nós não estamos exatamente em desacordo com a ideia deque a noção de "esperança" possa estar ligada às crianças e, num sentido semelhante, à infância. Essa hipótese parece bastante razoável. Ora, qual é nossa objeção à essa articulação? A noção de tempo. As crianças, tanto quanto a infância, têm sido projetadas como expectativas de um futuro melhor. Pois bem, embarcando nas considerações feitas pelo poeta brasileiro Vicente Cecim, "a infância é o que existe de mais antigo em todos nós" 15 . De onde, defendemos que a infância está registrada no passado, como condição de possibilidade privilegiada de promoção de novos regimes de existência. O que longe de ser uma retórica utopista localizada num futuro distante e inalcançável, significa uma topia. Por isso, em nossa investigação consideramos oportunas as pistas no contexto da Conferência Internacional sobre Crianças, Repressão e Lei na

\footnotetext{
${ }^{15}$ De 28 a 31 de agosto de 2017, por ocasião do evento II Congresso Métodos Fronteiriços realizado na Universidade Federal de Rondônia (UNIR), tive a oportunidade de conhecer pessoalmente o poeta Vicente Cecim, autor do livro O escuro da semente.
} 
África do Sul sob o apartheid realizada em Harare, Zimbábue, em setembro de 1987. Na ocasião, Angela Davis disse que mesmo "sofrendo tanto quanto e, às vezes, muito mais do que" adultos; "as crianças da África do Sul mantêm seu indomável espírito de resistência" (DAVIS, 2017, p.95). A filósofa estadunidense ressaltou que as crianças foram uma fonte inesgotável de inspiração para pessoas adultas na luta contra o sistema de apartheid e que elas continuaram "dançando, cantando, mantendo viva a audaciosa crença na liberdade" (Idem, p. 96). A filósofa Angela Davis traz uma perspectiva notável, as crianças teriam justamente uma disposição profunda de se erguerem contra o autoritarismo.

Nossa inferência, considerando essas conjecturas da filósofa é bastante simples. Existe uma noção africana de infância que sustentaria essa afirmação, ndaw. A palavra é formada por um radical e um, por assim dizer, prefixo. "Daw" significa correr em língua portuguesa, com o acréscimo da letra "n" se transforma em infância. A palavra do idioma wolof interpretada a partir de seu significado etimológico quer dizer algo como: capacidade de correr, percorrer caminhos e encontrar rotas diversas.

\section{Berços civilizatórios de Diop}

Cheikh Anta Diop (1923-1986) foi um dos maiores pensadores do século $\mathrm{XX}$, a vasta envergadura de seu trabalho rompeu fronteiras entre as Ciências Exatas, da Natureza e Humanas. Diop tinha formação em História, Filosofia, Matemática e Física. Aos 24 anos, foi assistente da primeira mulher branca a ganhar o Prêmio Nobel de Física, a polonesa Marie Curie (1867-1934). Diop transitava com facilidade entre as diversas áreas, dentre suas teses vale a pena destacar a ideia de que existia na antiguidade da humanidade dois berços civilizatórios básicos. Os universos culturais euro-semitaasiático tinham em comum uma maior propensão para a violência, para o expansionismo, o individualismo e o materialismo porque estavam alicerçados no que Diop definiu como berço setentrional. Enquanto o berço civilizatório africano denominado de meridional era caracterizado pela matrifocalidade ${ }^{16}$ e gemelaridade ${ }^{17}$ criando condições xenófilas para um gerenciamento dos conflitos em que os adversários não precisam ser destruídos.

A partir desse panorama brevíssimo de alguns aspectos do pensamento de Cheikh Anta Diop, apostamos no uso afroperspectivista de sua notável contribuição. Aqui interpretamos que o berço meridional pode ser denominado como sociedades infancializantes. Enquanto o berço setentrional seria "sinônimo" de sociedades adultescidas. Num caso, a adultidade ${ }^{18}$ seria o modo de vida estruturante. No outro, o estado de infância. $\mathrm{O}$ que se configuraria como

\footnotetext{
${ }^{16}$ Matrifocalidade é a tese de que algumas sociedades africanas tradicionais estavam centradas nas mulheres. O que seria um contraponto ao sistema patriarcal.

${ }^{17} \mathrm{O}$ termo "gemelaridade" é usado pela pensadora Marimba Ani para designar que os "opostos" são complementares; não adversários.

${ }^{18} \mathrm{O}$ termo adultidade apareceu num trabalho de campo feito com um grupo focal de 20 crianças numa escola privada na cidade de Duque de Caxias-RJ nos dias 30 de novembro de 2017; 05, 11 e 13 de dezembro de 2017. No contexto de uma investigação piloto do projeto de pesquisa infância falante. $\mathrm{Na}$ ocasião, a estudante Olivia Griot, 8 anos, $3^{\circ}$ ano do Ensino Fundamental reclamou da "adultidade" como um modo de opressão e dominação.
} 
uma diferença entre duas grandes maneiras de organização social, cada uma baseada num tipo de cosmovisão/cosmosensação da realidade. Em termos filosóficos, circunscrevemos a ideia de sociedades infancializantes, ou ainda, brincantes sob o conceito de civilização meridional. A palavra "infancializante" deriva de outro neologismo, infancializar. Este por sua vez, uma interpretação advinda da infância como ndaw, o que difere da ideia de infância derivada de infantia, de onde vem o verbo: infantilizar. Dito isso, é importante mencionar que a civilização setentrional diopina vai ser denominada de sociedade adultescida. Neste caso, adultescimento é antônimo de infancialização, tendo o significado específico de adulteração da condição infancializante da existência, terrixistir. Em outras palavras, interpretamos que as bases filosóficas para esses dois "modelos" de organização social estariam alicerçadas na cosmovisão da adultidade - berço setentrional. Enquanto, o berço meridional estaria demarcado pela cosmovisão do estado de infância.

\section{O tempo em afroperspectiva}

Outro elemento importante para pensar a infância em afroperspectiva é a temporalidade. Sem dúvida, existem diversas maneiras de abordar o tempo. Para os fins da nossa discussão, iremos destacar uma concepção de tempo dominante no contexto cultural do ocidente em contraste com uma perspectiva muito comum no complexo cultural africano e da sua diáspora. Grosso modo, o ocidente conceberia o tempo como um fluxo em que o futuro é a possibilidade histórica de redenção. Enquanto, sem pensar em redenção ou salva- ção depois de uma batalha maniqueísta final, em afroperspectiva, o tempo faria um movimento no sentido do passado. Daí, o conflito tradição e modernidade, assim como todas suas derivações e implicações. Um elemento recorrente no projeto ocidental é a promessa de um futuro melhor, seja nos textos sagrados do contexto judaico-cristão, ou nos sistemas políticos liberais e socialistas. A “salvação” estaria no futuro, seja num paraíso celeste, num mercado que regula as relações econômicas ou num Estado que planeja a economia e instaura a igualdade.

A partir de leituras afrocentradas, o contexto africano se orienta em favor do passado. $\mathrm{O}$ que significa buscar na tradição uma alternativa para o presente. Eduardo David Oliveira faz um levantamento interessante em Cosmovisão africana: elementos para uma filosofia afrodescendente. De acordo com Oliveira, o tempo nas sociedades africanas se organiza em torno da tradição. Enquanto, o tempo ocidental se orienta em função do futuro. O que na perspectiva do filósofo significa uma severa diferença de orientação política. Nós aqui interpretamos isso da seguinte maneira, trabalhar em prol de um futuro melhor indica o desejo de nos tornarmos algo que ainda não somos. $\mathrm{O}$ esforço de "olhar para trás" significa reconhecer no presente alguma coisa que ainda permanece em todos nós, isto é, a infância.

Uma incursão nas culturas africanas tradicionais pode ajudar a compreender o que estamos a dizer. Para fins de elucidação da relação entre tempo e infância, vamos contrastar a maneira como o "tempo" tem sido pensado na maioria das conjecturas de matriz ocidental com a perspectiva de tempo no que aqui vamos denominar de para- 
digma africano. Não é raro que a ideia de utopia no mundo ocidental esteja vinculada ao futuro. Nós vamos lançar mão dos conceitos trabalhados pelos filósofos John Mbiti (1931) e Friedrich Hegel (1770-1883). O queniano contribui com uma noção de tempo em que o passado é mais relevante do que o futuro. $\mathrm{O}$ alemão defende que o futuro é o resultado de um processo de avanço, sofisticação e elaboração da consciência. O filósofo John Mbiti que posiciona a temporalidade africana como um tipo de fluxo que caminha para o passado. Não raramente, autoras e autores europeus e, principalmente, o senso comum ocidental versam sobre o tempo como uma categoria caracterizada pelo movimento. No que diz respeito ao conceito de tempo, os filósofos alemães Baumgarten, Kant e Wolff convergem, a ideia de que o tempo como "ordem de sucessões", futuro se transforma em presente e este em futuro. De maneira geral, a concepção ocidental de tempo tem um modelo em que o passado é indefinido e o futuro é infinito. A dialética hegeliana teria consagrado ao futuro a missão de agregar o momento da grande superação, o passado seria um estágio mais primitivo. Na relação entre o tempo e a história na doutrina hegeliana, a razão tende a se realizar no futuro. $\mathrm{Ou}$ seja, com o tempo a dimensão da razão chegará à conclusão. Em outras palavras, o futuro vai ser melhor. $\mathrm{O}$ que parece com a linha abaixo:

\section{(Passado).............Presente ___ Futuro}

Na leitura do filósofo queniano John Mbiti, o tempo na concepção africana não segue no sentido do presente. Mas, ao "con- trário", o tempo aponta para o passado. $\mathrm{O}$ tempo é um fenômeno bidimensional, o presente integra o passado. $O$ futuro é tido como uma virtual ausência. O passado é a dimensão temporal longa e definida. Abaixo, o modelo:

\section{Passado___ Presente ......... (Futuro)}

O que significa uma temporalidade que se desenha a partir do passado? A experiência "do passado ela atualiza o presente e desdenha do futuro, pois não há futuro no mundo da experiência" (OLIVEIRA, 2012, p.40). O filósofo Eduardo David de Oliveira faz uma bela argumentação no livro Cosmovisão Africana no Brasil: elementos para uma filosofia afrodescendente, encontramos o tempo como um conceito filosófico bidimensional composto por passado e presente. O futuro está fora da arena da experiência, dos acontecimentos e não pode ser considerado. O que importa é o presente e como o passado é capaz de "sustentá-lo". Nossa especulação filosófica afroperspectivista traz um contraste. Existiria um desejo por um futuro melhor por parte da ideia de tempo dominante de registro ocidental. Enquanto utopia futurista. A diferença em relação a concepção de tempo de matriz africana estaria justamente.

Daí, podemos ensaiar o seguinte. $\mathrm{O}$ ocidente estaria majoritariamente interessado em desenvolvimento e caminhar no sentido de um futuro. Enquanto um modelo cultural dinâmico e complexo, a África estaria interessada no presente, o que implica em nunca desprezar o passado. 
Nossa conjectura é a seguinte. Grosso modo, podemos dividir as perspectivas sobre o tempo em duas. O tempo da adultidade. E, o tempo da infância. No primeiro caso, estamos diante de uma experiência do tempo em que o passado e o futuro atravessam o presente, deslocando o sujeito do instante. O tempo da adultidade é uma experiência em que o sujeito não consegue estar inscrito consigo mesmo no instante presente. Por outro lado, o tempo da infância não significa a experiência temporal de estar criança. Porém, um modo de experimentação da vida que, sem desprezar o passado, reconhece que o presente tem que ser vivenciado em atenção plena.

\section{Concepções de infância}

Nas sociedades ocidentais, um dos marcos dos estudos sobre a infância está numa publicação de 1960. Através de uma vasta pesquisa analisando iconografias religiosas e leigas das Idades Média e Moderna de países europeus, o historiador Philippe Ariès (1914-1984) traz duas teses que merecem destaque. A primeira preconiza a "descoberta da infância" como um acontecimento que se deu por volta do século XVII. A tese seguinte reza que com o abandono da noção de que a criança era simplesmente um adulto em miniatura (ARIÈS, 1981, p. 18), a infância ganha relevância e novas possibilidades começam a ser desenvolvidas e sistematizadas.

No século XVII, entretanto, a criança, ou ao menos a criança de boa família quer fosse nobre ou burguesa, não era mais vertida como os adultos. Ela agora tinha um traje reservado à sua idade que a distinguia dos adultos. Esse fato essencial apa- rece logo ao primeiro olhar lançado às numerosas representações de crianças do início do século XVII (Idem, p.7o)

Para Ariès, a emergência do "sentimento da infância” traz novas práticas sociais, políticas de assistência, cuidados familiares específicos, indumentária diferencia$\mathrm{da}^{19}$ e uma atenção especial da escola. A obra História Social da Criança e da Família é um divisor de águas por revelar novas disposições em relação à infância. Ao longo da história do ocidente, a infância foi vista tanto como sinônimo de barbárie (PLATÃO, 2010) quanto de candura (ROUSSEAU, 1995).

(...) entre todas as criaturas selvagens, a criança é a mais intratável; pelo próprio fato dessa fonte de razão que nela existe ainda ser indisciplinada, a criança é uma criatura traiçoeira, astuciosa e sumamente insolente, diante do que tem que ser atada, por assim dizer, por múltiplas rédeas (...) (PLATÃO, 2010, p. 302).

Séculos mais tarde, a modernidade iria associar infância e inocência. O cristianismo hegemônico na Europa interpelava a criança dentro da perspectiva de pecado original (AZEVEDO \& LIMA, 2013). O filósofo britânico John Locke (1632-1704) fez um leve deslocamento parcial da culpa imputada à infância; afinal advogava que todas

\footnotetext{
19 É importante frisar que na Europa a mudança do traje tinha recorte social e de gênero. Os meninos nobres e burgueses começaram a fazer uso de vestimentas específicas para crianças, o que demorou mais tempo para crianças pobres em geral e, sobretudo, no caso das meninas.
} 
as crianças eram tabulas rasas, nem más e nem boas, alforriando-as do pecado; mas, ainda considerava que a criança sofria de uma enfermidade natural e precisava de tutela. Foi adiante com o filósofo suíço Jean-Jacques Rousseau (1712-1778) que encontramos uma sistematização teórica que favorece a visão romântica que surge na $\mathrm{Eu}$ ropa do século XVIII e vai fortalecer no seguinte. Para Rousseau, a criança é inocente por natureza. Ora, se o iluminismo desenvolveu e reiterou a ideia de que a infância precisava ser superada com rigor e velocidade. Rousseau desenvolveu a cautela em esperar que a criança se desenvolva sem pressa, bastaria isolá-la do mundo adulto corrupto e degenerado. Sem dúvida, autores ocidentais como Jean-François Lyotard (1924-1998), Gilles Deleuze (1925-1995), Giorgio Agamben (1942), dentre outras e outros, têm feito contribuições significativas para deslocar a infância desse lugar de ausência e falta. Walter Kohan traz importantes formulações neste sentido. O filósofo argentino afirma: "a infância é o nome de um milagre, o da interrupção do ser das coisas pela entrada de seu outro, do outro do ser, a condição de toda e qualquer diferença" (KOHAN, 2010, p. 225). Essa notável passagem está a dizer que a infância é a condição de possibilidade de toda diferença. Um conceito disruptivo e contundente. Um milagre.

Diante desse brevíssimo sumário recortado e incompleto de concepções da infância no ocidente; resta perguntar o que sabemos a respeito de perspectivas africanas? Uma filósofa que nos ajuda a fazer uma aproximação da concepção de infância é a costa marfinense Tanella Boni (1954).
Nos anos de 2013 e 2016, Tanella Boni ofertou poemas para a exposição Gentú Ndaw (Sonhos de Infância) com fotografias do cotidiano de crianças do Mali, Gana, Costa do Marfim, Níger, Togo, Burkina Faso, Senegal e Gâmbia do artista Ângel Luis Aldai. Em certa medida, os poemas convergem com as observações feitas por Amadou Hampâté Bâ (1900-1991) em Amkoullel, o menino fula (2003), a saber: a memória está no registro da infância. Conforme Bâ, o menino fula desde criança foi convidado a escutar histórias, saborear as palavras. Afinal, só é possível memorizar na condição de infância. Em outras palavras, a memória não seria algo apenas do registro da ancestralidade. Ela não deve ser entendida como propriedade exclusiva das pessoas mais velhas. As crianças e as pessoas investidas de infância guardam a tradição. Por excelência, infância e tradição são sinônimos. Porque um esforço tradicional africano está justamente na preservação da infância. Nós podemos discorrer mais sobre a concepção africana de infância nas interpretações de histórias tradicionais com crianças. Uma das mais populares e revisitadas narrativas é o conto popular da cultura wolof, Kiriku e a feiticeira. O conto faz parte do "Império Wolof civilização formada por cinco reinos: Waalo, Kayor, Baol, Sine e Saloum aproximadamente de 1360 a 1890 na África ocidental" (NOGUERA, 2017, p.366). O conto se transformou num desenho animado ${ }^{20}$. Nossa

\footnotetext{
20 Essa história tradicional do povo Wolof que foi transformada em filme e estreou em 1998, depois de uma produção que envolveu três países europeus sob a direção do francês Michel Ocelot, que passou a infância em Guiné-Bissau.
} 
interpretação é de que a tônica da história é repercutir o conceito de infância como um sentido (NOGUERA, 2017a; NOGUERA 2017b). Infância pode ser lida como uma categoria geracional, isto é, uma fase da vida específica. Porém, nos interessa outra dimensão da infância. A noção de que ela significa um sentido humano, ao lado de olfato, visão, paladar, tato e audição. Infância seria justamente a possibilidade de produção de cosmosensações inéditas diante dos desafios da vida. Entendendo aqui que a categoria cosmosensação sistematizada pela socióloga nigeriana Oyeronke Oyewumi faz contraponto com o conceito mais recorrente de cosmovisão do filósofo estagirita Aristóteles. De volta ao conceito de infância sob às luzes afroperspectivistas, consideramos pertinente afirmar que ele recobre a possibilidade de lançarmos perspectivas inaugurais sobre o mundo, encontrar outras alternativas para questões antigas e recuperar possibilidades pouco frequentadas diante de velhos problemas. A infância é o que torna possível a todos os seres vivos criar novos modos de vida. O que empobrece a vida é justamente a destituição da infância, a saber: o adultescimento. Neste sentido que usamos o verbo "infancializar" para não confundir com "infantilizar" - verbo que ressalta somente o caráter geracional da infância. Infancializar significa estado de infância em exercício, assumir o mundo como uma surpresa inexplicável e que a existência só é possível como exercício brincante. Dito de outro modo, a única maneira de existir é como sujeito brincante. A brincadeira é:
(...) necessária para adultos e para a sobrevivência. É preciso entender que brincar é algo mais profundo do que simplesmente jogar uma bola ou rolar um carrinho. É algo que está conosco há milhares de anos, uma herança ancestral e que espera para ser incorporada desde a nossa infância. Fomos biologicamente projetados para brincar e é por isso que a brincadeira precisa fazer parte da nossa cultura (BROWN, 2015).

Nós estamos de acordo com pesquisas do psiquiatra estadunidense Stuart Brown no NifPlay [National Institute for Play (Instituto Nacional de Brincadeira)], brincar é essencial para viver. Infancializar remete justamente a reconhecer que a vida é uma experiência brincante. Para Brown, pessoas adultas devem brincar para existir com bem-estar. A infância, assim como a brincadeira, pode ter ficado no passado; mas, nunca é tarde demais para nos reencontrarmos com ela.

\section{Sankofa}

Se wo were fi na wo sankofa a yenkyi. Provérbio Akan

No contexto da cultura do tronco linguístico Akan, nós encontramos símbolos Adinkra (NASCIMENTO; GÁ, 2009). A epígrafe significa algo aproximado como: "Nunca é tarde para voltar atrás e apanhar o que ficou para trás”. Ora, aqui interpretamos que esse passado a ser recuperado é a infância. A infância não num sentido restrito, entendido como estar criança. Porém, como a condição genuína da existência. Afinal, uma leitura que identificasse "o que 
ficou para trás” com a infância individual seria empobrecedora.

Vale comentar um pouco a respeito dos povos Akan. É importante fazer notar que Akan é um tronco étnico-linguístico que recobre várias etnias. Ou seja, Akan é um conjunto de línguas nígero-congolesas faladas no Golfo da Guiné, atualmente concentradas na Costa do Marfim e em Gana. As etnias do tronco Akan são: Akuapem, Akyem, Asante, Baoulé, Anyi, Brong, Fonte e Nzema.

Conforme a oralitura - a sistematização da "escrita oral" - sobre a organização Adinkra, durante uma guerra do rei do povo Asante, Osei Bonsu, contra o rei Kofi Adinkra do povo Gyaaman. O rei de Gyaaman copiou um símbolo real Asante. Após uma batalha difícil, Osei Bonsu sagrou-se vencedor e passou a incorporar os símbolos do rei Kofi Adinkra, os quais tinham influências dos povos mallam e denkyira. Desde então, os Asantes passaram a organizar essa escrita filosófica, histórica e cultural num tipo de "catálogo" denominado de Adinkra. No século XX, os estudos do professor Kwaku Ofori-Ansa da Universidade de Howard (NASCIMENTO; GÁ, 2009, p.23).

Dito isso, vamos adentrar na relação entre o símbolo sankofa em seu sentido filosófico no contexto da proposta de sustentar a infância em afroperspectiva. Eis, o símbolo:

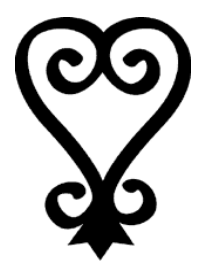

Figura or Adinkra Sankofa, fonte: (LARKIN \& GÁ, 2009, p.41)
Encontramos variações, dentre outras, como abaixo:

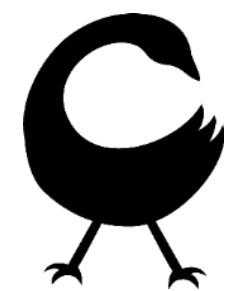

Figura 02 Adinkra Sankofa, fonte: (LARKIN \& GÁ, 2009, p.41)

Sankofa é descrito como símbolo da sabedoria e do conhecimento, a ideia de que devemos aprender como passado para nos erguermos no presente e no futuro. É importante notar que sankofa é a terceira e etapa de um processo que começa com sankohwe (retornar para ver) seguida de sankotsei (retornar para ouvir, estudar).

Nossa conjectura é de que esse exercício só é possível porque o passado inclui justamente a infância. Daí, nossa especulação filosófica: o passado é aquilo que existe de mais antigo em todos nós, a nossa infância. No caso da ancestralidade africana, o passado está na infância - momento em que somos capazes de incorporar a dinâmica complexa da vida. Nós interpretamos sankofa como sendo justamente a primeira condição existencial de todos os seres, infância.

\section{Conclusões parciais}

Se você souber de onde veio, saberá para onde está indo. ${ }^{21}$ Baba Diakité

A epígrafe que abre o tópico de encerramento deste artigo tem uma peculiari-

${ }^{21}$ DIAKITÉ, Baba, O dom da infância, p.9 
dade. Apenas somos capazes de entender nossa jornada quando reconhecemos de onde partimos. O que está em jogo em qualquer chegada, até mesmo na caminhada, é a partida. O ponto de partida nunca deve ficar encoberto. $\mathrm{Na}$ abertura de $\mathrm{O}$ dom da infância: memória de um garoto africano do malinense da etnia fulani Baba Wagué Diakité, nós encontramos uma bela passagem, um provérbio do seu povo que diz: "Den be ik bogo kènè. A mana dilan cogo min, a bè já a cogo la”. O que quer dizer algo como, "A criança nada mais é do que barro molhado. Seca da forma que é molhada”. Ora, à primeira vista poderíamos ler que essa condição da infância será um demérito, ou ainda, uma prova de que as crianças nunca são capazes de ter uma firme posição diante das coisas. Pois bem, não se trata de ser fácil de manipular num sentido pejorativo e destituído de autonomia. Mas, sim de uma característica fundamental da infância, um tipo de plasticidade existencial que faz com que as pessoas investidas de infância possam aprender continuamente e nunca permitir que o "barro seque", isto é, sempre estão dispostas a reconhecer que a destreza da vida é algo que continua por fazer. Tal como nos diz o filósofo egípcio Ptahhotep, um dos baluartes da filosofia africana antiga.

Não te envaideças de teu conhecimento, toma o conselho tanto do ignorante quanto do instruído, pois os limites da arte de filosofar (rekhet) não podem ser alcançados e a destreza de nenhum artista é perfeita. O bem falar (a palavra perfeita) é mais raro do que esmeralda, mas pode encontrar-se entre cria- dos e britadores de pedra (PTAHHOTEP, 200o, p. 247).

Em outros termos, esse espírito filosófico proposto pelo pensador Ptah-Hotep expressaria, essa é nossa interpretação, o estado de infância. $\mathrm{O}$ que contrasta com a adultidade. Enquanto, a expressão conceitual "estado de infância" recobre várias ideias e noções, conotando um tipo de espírito filosófico diante da vida. A capacidade de fazer uso da dúvida como ferramenta que fomenta ações, promove questionamentos e assume que as respostas podem ser temporárias e que isso não as invalida. A adultidade é a necessidade de vencer os adversários sem problematizar os seus próprios princípios, sem capacidade de escuta das ideias diversas. Enquanto, o estado de infância é uma perspectiva que reconhece que podemos aprimorar nossa maneira de interpelar o mundo sempre que estivermos abertos a repensar o que pensamos.

Dito isso, vale a pena retomar a citação que abre este tópico: "Se você souber de onde veio, saberá para onde está indo" (DIAKITÉ, 2012, p.9). Numa leitura afroperspectivista isso quer dizer que o movimento de retornar para ver o que ficou para trás significa assumir a condição de uma experimentação do que é mais antigo e primeiro em todos os seres, a infância. Cabe uma definição, a partir do turbilhão multifacetado de referências, definimos infância (ndaw) como um sentido, ao lado de outros sentidos humanos, uma cosmosensação em que as experiências de olhar, ouvir, tocar, sentir sabores e experimentar odores são notáveis e inaugurais. Ou seja, significa en- 
trevistar a rotina como se fosse a primeira vez, ou ainda, encontrar familiaridade no inusitado. $\mathrm{O}$ que é coextensivo à terrixistir, isto é, só é possível vivenciar esse modo de interpelar a realidade se existirmos em parceria com outras pessoas e com o lugar em que estamos. $\mathrm{O}$ que significa que nunca podemos estar vivos e presentes no mundo destituídos de relações com outros seres. Dito isso, sankofa remeteria justamente ao mergulho naquilo que fomos e ainda existe em todos nós, a infância que torna possível reinventar a vida e percorrer jornadas que não foram percorridas. Neste sentido, a infância é a possibilidade de percorremos novos erros, isto é, caminhos que não sabemos exatamente para onde apontam.

Diante de tudo isso, o que significa propor a infância em afroperspectiva? Assumir que a infância inscreve-nos uma provocação grave e profunda. O papel da cultura não é o desenvolvimento de uma sociedade, tampouco fazer da vida, em sua dimensão individual, um projeto de amadurecimento. Pelo contrário, o objetivo mais radical da existência estaria em nunca esquecermos de nossa infância, daquilo que nos torna seres viventes: a capacidade de reinventarmos a nós mesmos e o mundo de acordo com as necessidades próprias de existir. Daí, a necessidade de fazer com que essas três noções possam estar articuladas para nos situarmos politicamente diante da principal tarefa da vida, produzir a extensão da infância para além da fase geracional e jurídica de ser/estar criança.

A infância em afroperspectiva é uma provocação política e, em certa medida, existencial, trata-se da instituição de um projeto em favor de um deslocamento radical. Não estamos apostando no desenvolvimento, no avanço e no progresso. Nossa aposta é quase uma inversão, voltar ao tempo em que brincar era a única maneira de nos relacionarmos com outros seres, conosco e com o mundo. É preciso nos assegurarmos de que o afastamento da infância é um dos maiores obstáculos, quiçá o mais forte, a criação de novos modos de vida. Por isso, a convocação teórica para um novo olhar sobre/a partir/ desde a infância. Afinal, racismo, assim como misoginia, machismo, lgbtfobia ${ }^{22}$, adultocentrismo, discriminação de pessoas com deficiência e todas as formas de opressão não têm soluções mágicas. Mas, nossa aposta teórica é de que as alternativas passam pela infância. Por essa infância que descrevemos como condição de experiência humana. Por isso, entendemos que a inclusão de estudos africanos e afro-brasileiros no currículo e como demanda política antirracista não deve contribuir para mera inclusão da população negra no mundo branco. Não se trata mais de "incluir" num mundo pronto e constituído. Mas, na constituição de novos mundos, realidades policêntricas, polirracionais, pluriversais que só são possíveis à medida que formos capazes de adentrar o estado de infância como uma maneira de entrevistar o mundo e experimentar a vida. Por fim, os maiores desafios, sejam filosóficos, políticos ou existenciais, estariam em permitir que a infância faça o milagre de reinventar o mundo.

\footnotetext{
${ }^{22}$ Lgbtfobia aqui é um conceito guarda-chuva que faz referência às discriminações contra populações de lésbicas, gays, bissexuais, transgêneros, transexuais, intersex e pessoas não-binárias.
} 


\section{Referências}

AGAMBEN, Giorgio. Infância e história: destruição da experiência e origem da história. Belo Horizonte: UFMG/Humanitas, 2005.

ALDAI, Angel; BONI, Tanella (poemas). Exposição fotográfica Géntu Ndaw (Sonhos de Infância) Casa Árabe, Madrid, 23/05/2016 a 17/07/2016.

ARIÉS, Philippe. História Social da Criança e da Família. 2. ed. Tradução de Dora Flaksman. Rio de Janeiro: LTC Editora, 1981.

ARROYO, Miguel G. "O significado da infância” In Anais do I Simpósio Nacional de Educação Infantil. Brasília, MEC/SEF/DPE/COEDI, 1994.

ASANTE, Molefi. “Afrocentricidade e Educação na senda do progresso: Brasil e EUA”. Tradução Ana Monteiro-Ferreira In CARVALHO, Carlos Roberto; NOGUERA, Renato; SALES, Sandra Regina. Relações Étnico-Raciais e Educação: contextos, práticas e pesquisas. Rio de Janeiro: NAU/EDUR, 2013, pp.23-34.

ASANTE, Molefi Kete. Afrocentricity: the theory of social change. 3 rd. ed. Trenton: Africa World, 1988.

ASANTE, Molefi Kete. “Afrocentricidade: notas sobre uma posição disciplinar”. In: NASCIMENTO, Elisa Larkin. Afrocentricidade: uma abordagem epistemológica inovadora. Tradução de Carlos Alberto Medeiros. São Paulo: Selo Negro, 2009. p. 93-110.

NASCIMENTO, Elisa Larkin; GÁ, Luiz Carlos (org.). Adinkra: sabedoria em símbolos. Rio de Janeiro: Pallas, 2009.

BÂ, Amadou Hampâté. Amkoullel, o menino fula. Tradução Xina Smith de Vasconcellos. São Paulo, Palas Athena/Casa das Áfricas, 2003.

BONI, Tanella. "A dignidade da pessoa humana: da integridade do corpo e da luta para o reconhecimento”. Revista tempo brasileiro, jan-mar. n. 168. Rio de Janeiro: Tempo Brasileiro, 2007.

BRASIL. Conselho Nacional de Educação. Conselho Pleno. Parecer CNE/CPoo3/2004. Diretrizes Curriculares Nacionais para a Educação das Relações Étnico-Raciais e para o Ensino de História e Cultura Afro-Brasileira e Africana. Brasília-DF; Ministério da Educação; 2004.

BRASIL: MEC. Orientações e Ações para a Educação das Relações Étnico-Raciais. Brasília: MEC/SECAD, 2006.

BROWN, Stuart. Durante toda a nossa vida, devemos brincar. Entrevista Revista Crescer. Disponível em: <http://revistacrescer.globo.com/Brincar-e-preciso/noticia/2015/10/durantetoda-nossa-vida-devemos-brincar.html> . Acesso em: 10 jul. 2016.

BUCKINGHAM, David. After the death of childhood: Growing up in the age of electronic media. Oxford, UK; Malden, MA: Polity Press/Blackwell, 2000.

VIVEIROS DE CASTRO, Eduardo. A inconstância da alma selvagem. São Paulo: Cosac Naify, 2002. 
VIVEIROS DE CASTRO, Eduardo. Metafísicas Canibais. Tradução Oiara Bonilla. São Paulo: Cosac Naify, 2015.

DAVIS, Angela. Mulheres, cultura e política. Tradução Heci Regina Candiani. São Paulo: Boi Tempo, 2017.

DELGADO, Ana Cristina; MÜLLER, Fernanda. “Abordagens etnográficas nas pesquisas com crianças" In CRUZ, Silvia Helena Vieira. A criança fala, a escuta de crianças em pesquisas. São Paulo: Editora Cortez, 2008.

DIAKITÉ, Baba Wagué. O dom da infância: memórias de um garoto africano. Tradução Marcos Bagno. São Paulo: Edições SM, 2012.

GOMES, Nilma Lino. "Alguns termos e conceitos presentes no debate sobre relações raciais no Brasil: uma breve discussão" In Educação antirracista: caminhos abertos pela Lei Federal no 10.639/o3. Brasília: MEC/SECAD, 2005. p. 39-62.

GRUBITS, Sonia; DARRAULT-HARRIS, Ivan. "Cultura e sociedade: ouvindo crianças indígenas através da produção artística” In: CRUZ, Silvia Helena Vieira. A criança fala, a escuta de crianças em pesquisas. São Paulo: Editora Cortez, 2008.

JENKS, Chris. Constituting the child. In: JENKS, Chris (Org). The sociology of childhood: Essential readings. London: Batsford, 1982.

JENKINS, Henry. Childhood innocence and other modern myths. In: JENKINS, Henry (org.). The children's culture reader. New York: New York University Press, 1998.

KOHAN, Walter Omar. Infância. Entre a Educação e a Filosofia. Belo Horizonte: Autêntica, 2003.

KOHAN, Walter. Infância, estrangeiridade e ignorância: ensaios de filosofia e educação. Belo Horizonte: Autêntica, 2007.

KOHAN, Walter. "Vida e Morte da Infância, entre o humano e o inumano" In Educ. Real., Porto Alegre, v. 35, n. 3, p. 125-138, set./dez., 2010, p.125-137.

KOHAN, Walter. "Visões de filosofia: infância” In: ALEA, Rio de Janeiro. Vol. 17/2, p. 216226, jul-dez 2015.

KI-ZERBO, Joseph (Org.). História Geral da África. Volumes I, II, III, IV. São Paulo: Âtica/ Unesco, 1982.

MARTINS, Cristiane; CRUZ, Silvia Helena. "Sob o olhar infantil: o conceito de criança na perspectiva da criança” In CRUZ, Silvia Helena Vieira. A criança fala, a escuta de crianças em pesquisas. São Paulo: Editora Cortez, 2008.

MBEMBE, Achille. Formas Africanas de Auto-inscrição. Tradução de Patrícia Farias. Estudos Afro-Asiáticos, Ano 23, no 1, 2001.

Necropolítica. Madrid: Editorial Melusina, 2011.

Crítica da Razão Negra. Tradução de Marta Lança. Lisboa: Ed. Antígona,

2014. 
M’BOKOLO, Elikia. África negra: história e civilizações. Salvador/São Paulo: EDUFBA/Casa das Áfricas, 2009. Tomo I (Até o século XVIII).

Elikia. África negra: história e civilizações. Salvador/São Paulo: EDUFBA/Casa das Áfricas, 2011. Tomo II (Do século XIX aos nossos dias).

MOORE, Carlos. Racismo \& Sociedade: novas bases epistemológicas para compreensão do racismo na história. Belo Horizonte: Mazza Edições, 2007.

, Carlos. A África que incomoda: sobre a problematização do legado africano no quotidiano brasileiro. $2^{2}$ edição (Revista e ampliada). Belo Horizonte: Nandyala, 2010.

NASCIMENTO, Abdias. O quilombismo: os documentos de uma militância panafricanista. Petrópolis: Vozes, 1980.

NASCIMENTO, Elisa Larkin (org.). Afrocentricidade: uma abordagem epistemológica inovadora. São Paulo: Selo Negro, 2009.

NASCIMENTO, Elisa Larkin. A matriz africana no mundo. São Paulo: Selo Negro, 2008.

NOGUERA, Renato. "Denegrindo a filosofia: o pensamento como coreografia de conceitos afroperspectivistas". In Griot - Revista de Filosofia, Amargosa, Bahia - Brasil, v.4, n.2, dezembro/2011, pp. 1-19.

NOGUERA, Renato. "Kiriku: heterônimo da infância como experiência e da experiência da infância” In Anais do Congresso de Estudos da Infância. - Rio de Janeiro, 2017a, pp.363370.

NOGUERA, Renato. "Pinóquio e Kiriku: infância(s) e educação nas filosofias de Kant e Ramose" In Revista AÚ, ano 02, 2017b, pp.5-18.

NOGUERA, Renato. Ensino de Filosofia e Lei 10639. Rio de Janeiro: Pallas/Fundação Biblioteca Nacional, 2014.

OLIVEIRA, Eduardo. Cosmovisão Africana no Brasil: elementos para uma filosofia afrodescendente. Curitiba: Gráfica e Editora Popular, 2006.

. A ancestralidade na Encruzilhada. Curitiba: Gráfica Popular, 2007.

OYEWUMI, Oyeronke. The Invention of Women: Making an African Sense of Western Gender Discourses. Minneapolis, MN: University of Minnesota Press, 1997.

PLATÃO. As leis, ou da legislação e epinomias. Tradução: Edson Bini. 2. ed. Bauru-SP: Edipro, 2010.

PTAHHOTEP. “Ensinamentos de Ptahhotep”. ARAÚJO, Emanuel. Escrito para a eternidade: a literatura no Egito faraônico. Brasília: Editora da Universidade de Brasília: São Paulo: Imprensa Oficial do Estado, p. 244-259, 2000.

QUIJANO, Aníbal. "Colonialidade do poder e classificação social”. In: SANTOS, Boaventura de Sousa; MENEZES, Maria Paula (Org.). Epistemologia do Sul. Coimbra: Almedina, 20o9, p. $73-118$.

ROUSSEAU, Jean-Jacques. Emílio ou da Educação. Trad. Sérgio Milliet. 3. ed. Rio de Janeiro: Bertrand Brasil, 1995. 
SANTOMÉ, Jurjo Torres. "As culturas negadas e silenciadas no currículo. In: SILVA, Tomaz Tadeu. (Org.) Alienígenas na sala de aula: uma introdução aos estudos culturais em educação. 8.ed. Petrópolis, RJ: Vozes, 2009.

SANTOS, Sales Augusto dos. “A lei no 10639/o3 como fruto da luta antirracista do Movimento Negro”. In: Educação antirracista: caminhos abertos pela Lei Federal no 10639/o3. Brasília: MEC, 2005.

SILVA, Wallace Lopes (org). Sambo, logo penso: afroperspectivas filosóficas para pensar o samba. Rio de Janeiro: Héxis Editora/Fundação Biblioteca Nacional, 2015.

SIROTA, Régine. "Emergência de uma sociologia da infância: evolução do objeto e do olhar", Cadernos de Pesquisa, São Paulo, n. 112, p. 7-31, mar. 2001.

SOLON, Lilian; COSTA, Nina; ROSSETTI-FERREIRA, Maria Clotilde. "Conversando com crianças" In CRUZ, Silvia Helena Vieira. A criança fala, a escuta de crianças em pesquisas. São Paulo: Editora Cortez, 2008.

SOUSA, Sônia M. Gomes. "O estudo da infância como revelador e desvelador da dialética exclusão-inclusão social” In CRUZ, Silvia Helena Vieira. A criança fala, a escuta de crianças em pesquisas. São Paulo: Editora Cortez, 2008.

SOUZA, Solange; CASTRO, Lucia. "Pesquisando com crianças: subjetividade infantil, dialogismo e gênero discursivo" In CRUZ, Silvia Helena Vieira. A criança fala, a escuta de crianças em pesquisas. São Paulo: Editora Cortez, 2008.

Recebido em: 05/06/2019

Aprovado em: 31/10/2019 